Conference Paper

\title{
A review of electrical motor topologies for aircraft propulsion
}

Bolam, R.C., Vagapov. Y. and Anuchin, A.

This is a paper presented at the 55th IEEE Int. Universities Power Engineering Conference UPEC2020, Torino, Italy, 1-4 Sept. 2020

Copyright of the author(s). Reproduced here with their permission and the permission of the conference organisers.

\section{Recommended citation:}

Bolam, R.C., Vagapov. Y. and Anuchin, A. (2020), 'A review of electrical motor topologies for aircraft propulsion.' In: Proc. 55th IEEE Int. Universities Power Engineering Conference UPEC-2020, Torino, Italy, 1-4 Sept. 2020, pp. 1-6. doi: 10.1109/UPEC49904.2020.9209783 


\section{A Review of Electrical Motor Topologies for Aircraft Propulsion}

\author{
Robert Cameron Bolam \\ Glyndwr University \\ Wrexham, UK
}

\author{
Yuriy Vagapov \\ Glyndwr University \\ Wrexham, UK
}

\author{
Alecksey Anuchin \\ Moscow Power Engineering Institute \\ Moscow, Russia
}

\begin{abstract}
This paper provides a review of the state-of-theart in aircraft electrical propulsion (AEP). Initially, the limitations of on-board energy storage devices are highlighted and contextualised. The definitions of useful measures for determining the suitability of motor design, namely specific power and motor torque per unit rotor volume (TRW), are discussed and relevant examples are provided. The classifications of motors used for terrestrial vehicle applications are reviewed and their limitations highlighted regarding their suitability to AEP applications. A discussion on motor configurations for aerospace applications is provided which includes: synchronous motor stator winding configurations; axial flux motor configurations and the causes of energy losses. Additionally, the topologies and performance characteristics of existing aerospace motor technologies are examined. It was concluded that electrical motors provide an ideal means for achieving aircraft propulsion and that higher motor speeds are likely to be required for future commercial aircraft motor designs.
\end{abstract}

Keywords-aircraft electrical propulsion, BLDC, unmanned aircraft, rim driven fan, $R D F$, specific power, TRV, slotless windings

\section{INTRODUCTION}

The comparatively low energy storage capacity of electrical aircraft is the only serious obstacle to the development of successful zero-emission flight. Although it is not the aim of this paper to discuss on-board electrical energy storage; it is first considered important to offer a contextual reference to the present feasibility of electrical propulsion for aircraft.

Various methods of electrical energy supply already exist to provide on-board power for propulsion. Fig. 1 provids an indication of power and energy densities of state -of-the-art electrical storage technologies. In [1] existing battery, solar cell, ultra-capacitor and fuel cell technologies are described alongside operational hybrid aircraft and future High-Temperature Superconducting (HTS) systems. HTS technology is becoming increasingly feasible with recent advances in material sciences [2],[3]. Likewise, high -powered metal-air battery technologies, such as lithiumair, offer the potential to equal and surpass the energy release capabilities of hydro-carbon fuels.

Fig. 1 provides an overview of theoretical specific energies of batteries compared with gasoline. Fig. 2. shows Ragone chart comparing specific energy and power values for electrical storage technologies. At the time of writing, the energy density of practical Lithium-Ion batteries is about $200 \mathrm{Wh} / \mathrm{kg}$ whereas Jet-A1 (AvTur) kerosene has an

This work is funded by the Welsh Government (WEFO) under the SMARTExpertise initiative (Project Reference 82321) and is supported by the European Regional Development Fund. energy density of $11.95 \mathrm{kWh} / \mathrm{kg}$ [2]. This is some sixty times greater than is achievable for electrical flight. Thus, it is restricting present aircraft applications to light weight, low speed and short duration flights such as light aircraft, paragliders, unmanned (autonomous) aircraft and model aircraft. Regardless of the means of on-board electrical energy supply, Aircraft Electrical Propulsion (AEP) is likely to bring about the most significant change to the topology of the electric motor for over a century. This paper presents a review of existing motor technologies for aircraft propulsion.

Two useful measures for determining the suitability of a motor design for a particular application are its Specific Power $(\mathrm{kW} / \mathrm{kg})$ and its Torque per unit Rotor Volume (TRV: $\mathrm{kNm} / \mathrm{m}^{3}$ ). The former provides an indication of performance regarding power to weight and allows a comparison to be made between electric motor performance and that of Internal Combustion Engines (ICE). Table I provides an approximate comparison of Specific Power values for traditional forms of vehicle engines.

The latter, TRV (refer to Table II), is a useful guide for designers in sizing an electrical machine as it provides an indication of the effectiveness of the electromechanical energy conversion of motor design. It can be calculated as follows [4]:

$$
\begin{gathered}
T R V=\frac{T}{V_{\text {rotor }}}=\frac{\pi}{\sqrt{2}} \times k_{w 1} \times A \times B=2 \sigma_{\text {mean }} \\
T=\frac{\pi^{2}}{4 \sqrt{2}} \times k_{w 1} \times A \times B \times D^{2} \times L_{\text {stk }} \\
V_{\text {rotor }}=\frac{\pi D^{2} L_{\text {stk }}}{4} \\
\sigma_{\text {mean }}=\frac{F_{\text {mean }}}{\text { Area }}=B \times A
\end{gathered}
$$

where $T$ is the motor torque $(\mathrm{Nm}) ; V_{\text {rotor }}$ is the rotor volume $\left(\mathrm{m}^{3}\right) ; D$ is the rotor diameter $(\mathrm{m}) ; k_{w 1}$ is the fundamental winding factor; $L_{\text {stk }}$ is the axial active length (m); $A$ is the electric loading: number of ampere-conductors per metre around the stator surface that faces the airgap; $B$ is the magnetic loading: the average flux density over the rotor surface (Tesla); and $\sigma_{\text {mean }}$ is the shear stress on the rotor $\left(\mathrm{N} / \mathrm{m}^{2}\right)$.

A variety of technical characteristics are used to classify motor types. Some sources broadly categorise motors as either AC or DC machines [5] whereas others draw a fundamental distinction between whether they have axial or radial flux topologies [6]. In an overview of electric machine technologies [7] an extensive range of existing and 


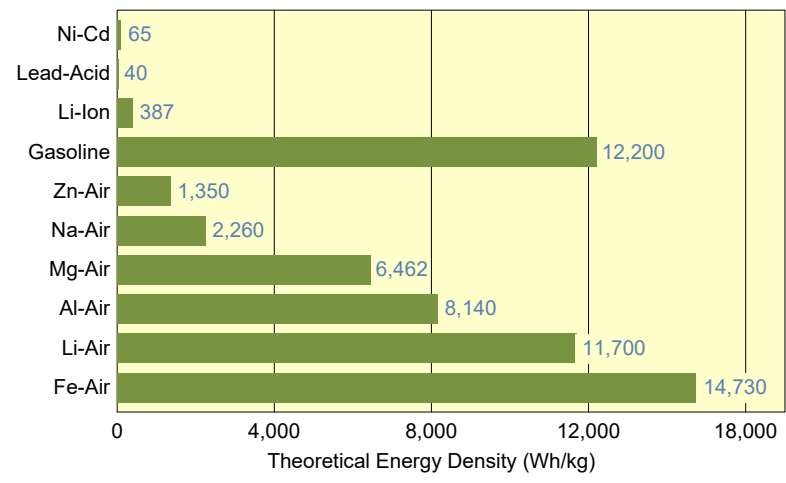

Fig. 1. Theoretical specific energies $(\mathrm{Wh} / \mathrm{kg})$ of batteries compared to gasoline [1].

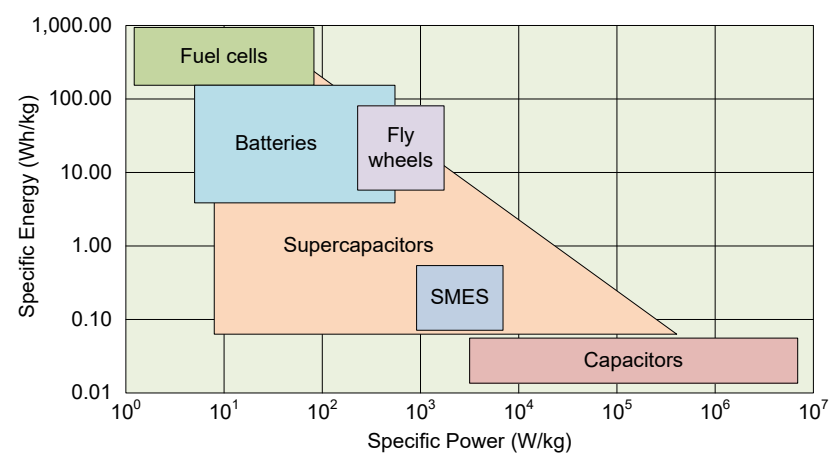

Fig. 2. Ragone chart comparing specific energy and power values for electrical storage technologies [1].

emerging motor concepts is provided, and these are initially categorised as brushed or brushless types. Another method of classification is based on whether the motor operation is synchronous or asynchronous. Fig. 3 shows a typical overall classification of motors used in modern electrical vehicle $(\mathrm{EV})$ traction applications.

The automobile sector has seen extensive development in EV motor technology over the past two decades. Over which time, it has become evident, that even though manufacturers' initial development specifications have

Table I. An Approximate Comparison of Specific Power Values for Traditional Forms of Vehicle Engines.

\begin{tabular}{|l|c|}
\hline \multicolumn{1}{|c|}{ Engine Type } & Specific Power (kW/kg) \\
\hline Automobile engine (reciprocating) & 0.9 \\
\hline High performance car engine (reciprocating) & 4.8 \\
\hline Jet engine & 31 \\
\hline Rocket engine & 153 \\
\hline
\end{tabular}

TABle II. Current TRV Values For Continuous Operation Motor Designs.

\begin{tabular}{|l|c|}
\hline \multicolumn{1}{|c|}{ Motor Type } & $\begin{array}{c}\text { TRV } \\
\left(\mathbf{k N m} / \mathbf{m}^{\mathbf{3}}\right)\end{array}$ \\
\hline Totally enclosed motors with low energy ferrite magnets & $5-15$ \\
\hline $\begin{array}{l}\text { Totally enclosed motors with sintered rare earth magnets } \\
\text { (NdFeB, SmCo) }\end{array}$ & $15-40$ \\
\hline Medium power $(>5 \mathrm{~kW})$ Industrial induction motors & $5-30$ \\
\hline Aerospace machines & $30-75$ \\
\hline Liquid cooled machines & $75-250$ \\
\hline
\end{tabular}

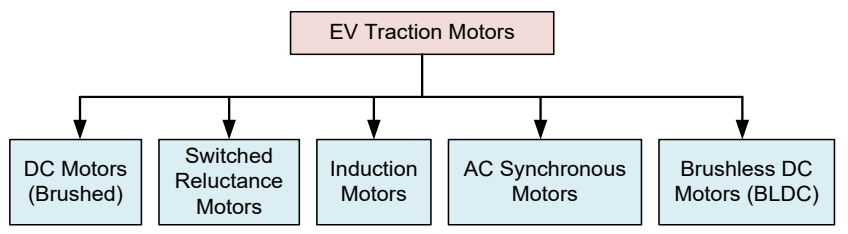

Fig. 3. Classification of motor types used in EV applications.

been similar at the outset of an EV design. Their resultant traction motor solutions have often varied. The Nissan LEAF motor, for example, is based on a Brushless DC (BLDC) permanent magnet motor design, whereas the Tesla model $\mathrm{S}$ motor is based on a copper rotor Induction Motor (IM). EV motors also vary considerably in the arrangement of their windings and their cooling provisions. In a comparative study [8] of different electric motors for EVs it was concluded that although induction motor technology was more mature, robust and less costly. Parment magnet synchronous motor motors provided less pollution, less fuel consumption and better power to volume ratios.

Until recently, electric motors in aerospace applications were mainly used to power on-board systems rather than being the primary method of propulsion. Over the past 20 years, the civil aerospace industry has concentrated efforts on developing More Electric Aircraft (MEA) technologies embodied by the Boeing 787 and Airbus 350 aircraft [9]. Large $(15 \mathrm{~kW})$ axial flow fans are used to recirculate air within the air-conditioning systems for civil airliners such as the Airbus A330 aircraft. Similarly, four $100 \mathrm{~kW}$ singlestage centrifugal compressors are used to pressurise the Boeing 787 fuselage. Electrically powered hydraulic and fuel pumps are common to many large aircraft designs, and electric motors incorporated in nose landing gear allow for more efficient ground taxi operations at airports [10].

\section{Motor Configurations for Aerospace Applications}

BLDC motor designs are currently the most commonly used for small unmanned AEP. They are very similar in design to synchronous AC motors with the primary difference being in the shape of their back-EMF waveform and rotor position sensing: BLDC motors have trapezoidal back-EMF waveforms; whilst synchronous AC machines generate sinusoidal shapes. Common BLDC configurations have the following characteristics and are more suitable for power drive applications that can withstand some torque ripple [8]:

- Full pitched and concentrated windings (generate trapezoidal back-EMF).

- Higher Power Density.

- Low cost Hall effect probes for motor commutation control.

There are two types of synchronous AC motors, namely wound-field (rotor) and permanent magnet [11]. The wound-field type requires brushes to provide an electrical current to the rotor. In common with brushed DC motor configurations, wound rotor AC machines are considered undesirable for aerospace applications on the grounds of their reduced component reliability and susceptibility to arcing. However, wound-field SMs (WFSMs) potentially have a future in HTS aerospace applications [3]. Permanent magnet (PM) AC synchronous motors are suitable for aerospace applications and considered preferable to BLDC 
motors for high speed applications as they offer better control and extended field weakening capabilities. AC synchronous motor operations have the following characteristics:

- Distributed and fractional-slot windings for sinusoidal back-EMF (providing smoother operation)

- Better control and extended field weakening capabilities (for high frequency control)

- High cost shaft encoder to control stator currents.

Induction motors (IMs) are used extensively in terrestrial applications and offer a simplicity of construction combined with low costs compared with BLDC machines as their construction requires no expensive rare-earth magnets. Stator windings for induction motors are identical to those of synchronous machines; however, IMs do not match PM machines for power density. IMs also experience performance restrictions due to thermal limitations imposed by rotor induction heating effects.

\section{A. Rotor and Stator Configurations}

Stator windings are categorised as either concentrated or distributed types. BLDC motors typically have concentrated stator windings, with conductor wires wound around salient iron pole pieces. In contrast, most PM synchronous motors have distributed windings with stranded or hairpin conductor coils housed in slots evenly distributed around the stator. Both of these winding types are susceptible, in varying degrees, to generating cogging and ripple torque effects owing to variations in their magnetic circuit reluctance [12]. For aerospace applications it is desirable to minimise any sources of noise, vibration and harshness (NVH) and increased attention is being given to slotless (airgap winding) BLDC motor configurations. In [13] a design method for a small-sized brushless DC motor double-layered, short pitched hexagonal winding is provided, which offers an advantage of omitting endwindings and their associated losses. The design and analysis of a lightweight motor for aerospace applications is presented in [14],[15], which achieves high power density, zero cogging torque and low torque ripple using a rotor magnet Halbach array arrangement. Halbach arrays improve airgap flux concentration and offer the future potential to delete the rotor iron from motor designs although not from their stator [16]. Various slotless winding patterns are presented including, helical, basket, skewed (Faulhaber), rhombic, straight (with end turns), ringed and pancake forms. Aspects of their design are discussed in [17] concluding that high frequency eddy current losses can be reduced by employing thinner conductors, such as Litz wire [18] and parallel connections. Favourable analysis and testing have also found that using aluminium windings instead of copper can provide improvements in motor specific power combined with cost benefits [19],[20].

\section{B. Axial Flux Motor Configurations}

Although the majority of motors are radial flux machines, axial flux PM motors attract much attention for traction and aerospace propulsion applications [21]. A comparison of the power density of axial machines is provided in [22] concluding that the axial machines analysed have higher power density when compared with IM machines. Unfortunately, this study does not provide a like for like comparison of BLDC technologies. Although, a similar comparison of axial and radial BLDC configurations [23] concludes that the axial flux machines have much higher torque to mass ratios than radial flux machines.

\section{Energy Losses}

The efficiency of aerospace electric motors and their associated controllers are critical to the success of commercially viable AEP systems. BLDC motors and their associated electrical speed controllers (ESCs), used for hobby build and small unmanned aircraft projects, commonly have unit efficiencies under $80 \%$. However, commercial AEP projects target efficiencies above $95 \%$ for motors and controllers alike. Thermal management of the power chain is critical to achieving these aims, and much effort is spent in reducing armature currents and controller switching frequencies. High DC line voltages e.g. $>500 \mathrm{VDC}$, allow for a significant reduction in current supply to stator windings, thus minimising the $\mathrm{I}^{2} \mathrm{R}$ losses. Motor cooling circuits, either liquid or forced air, can further enhance motor efficiencies. Advances in solid-state Silicon Carbide IGBT switching technologies have improved motor control performance as highlighted in a recent study [24], and for high altitude aircraft operations the high voltage DC (HVDC) motor transmission lines are susceptible to corona energy discharge losses [25]. An excellent performance analysis of electric motor technologies is provided in the White Paper produced by Motor Design Ltd. of the UK [26].

\section{Overview of Existing Aerospace Motor TECHNOLOGIES}

Table III provides an overview of a range of existing aerospace motor technologies sourced online from supplier literature. Some of the aircraft listed below are still in the development phase having not yet flown.

A graphical assessment of the achievable performance of these motors is provided in Fig. 4, in which motor powers have been plotted against motor speeds. It can be seen that the lower speed motors have high power applications because greater torque is required to turn large propellers. Such is the case for the magniX magni500, which is used to power the electrical version of the DHC-2 Beaver and also the Cessna Grand Caravan shown in Fig. 5.

Lower motor speeds permit direct coupling of propellers and provide a weight saving that would otherwise be incurred by a reduction gearbox. Aircraft with

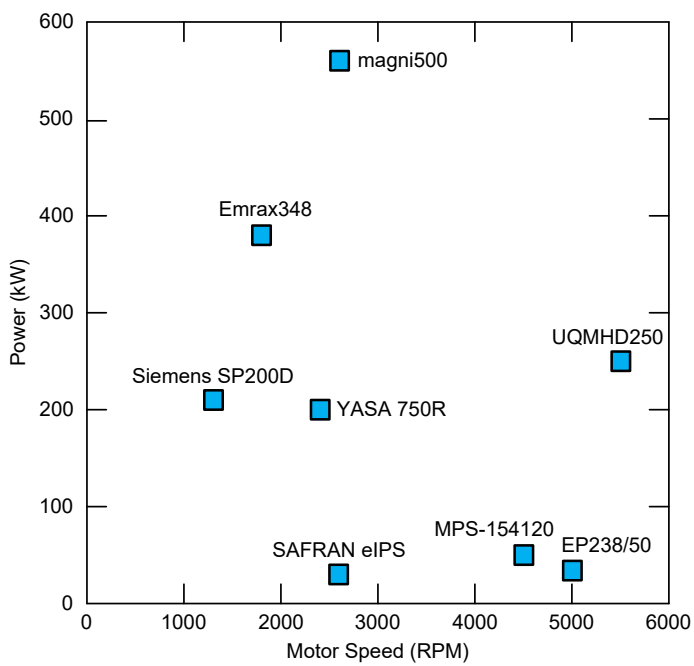

Fig. 4. Motor Powers versus Speed 
Table III. Existing Aerospace Motor Technologies.

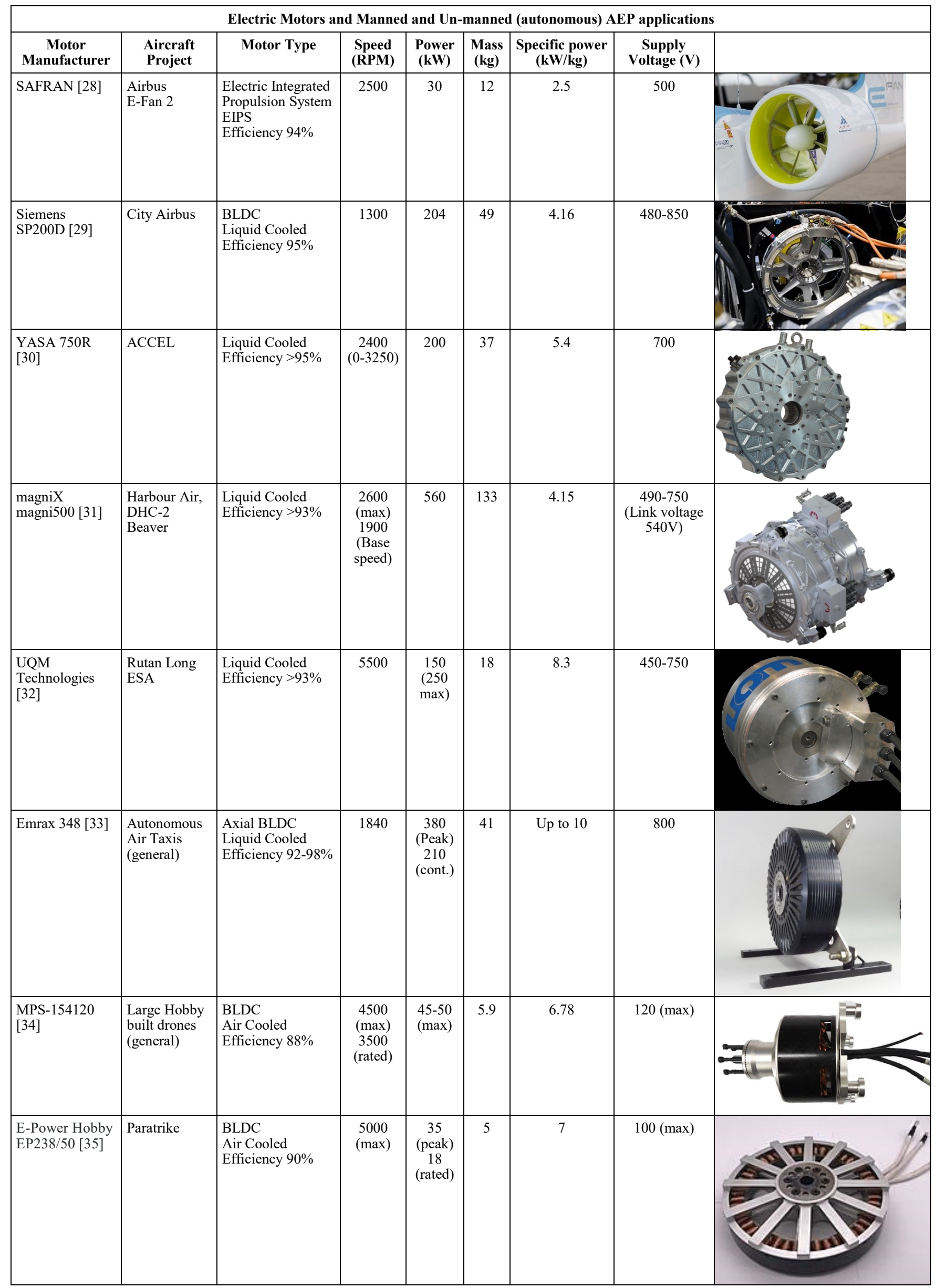




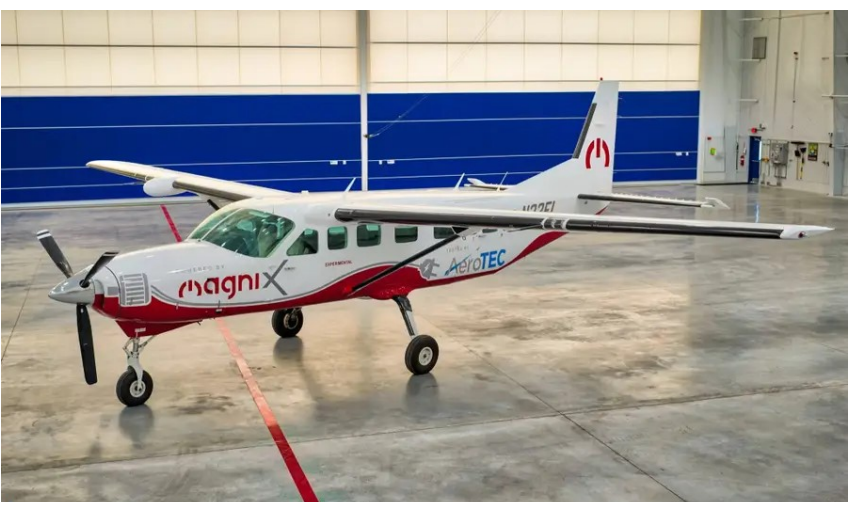

Fig. 5. Magnix powered Cessna Grand Caravan [36].

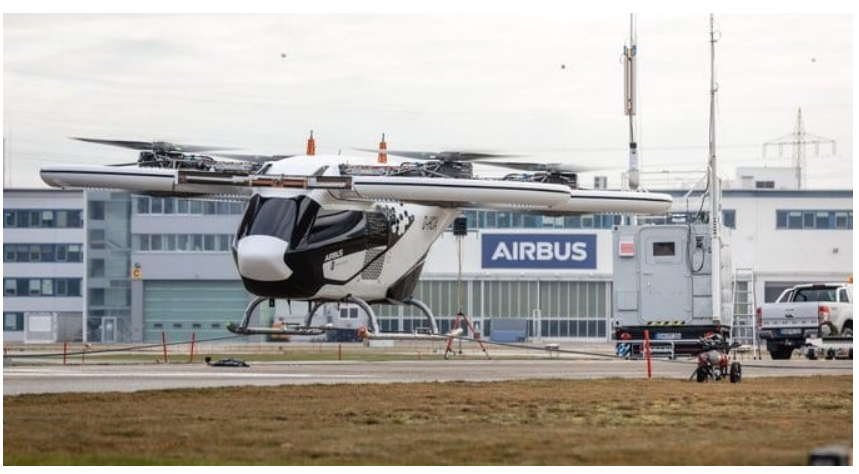

Fig. 6. Siemens powered CityAirbus [37].

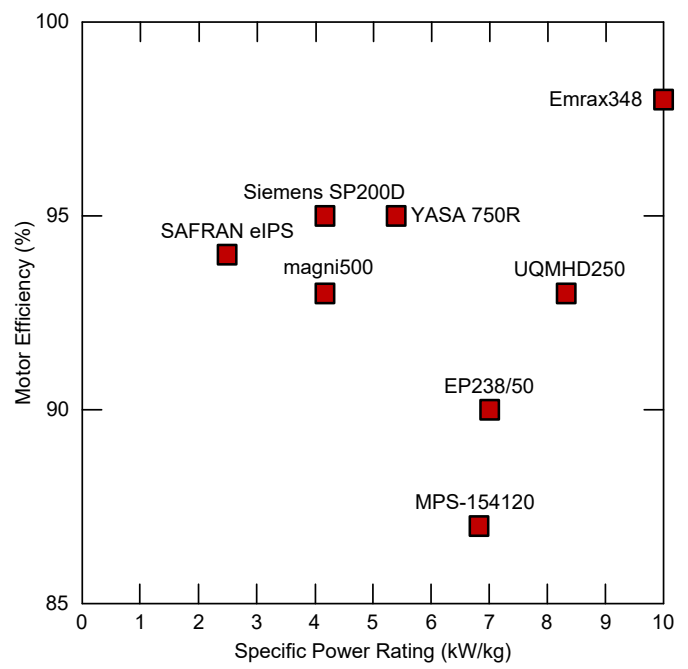

Fig. 7. Comparison of the Specific Powers and Efficiencies of the motors.

propellers exceeding $1 \mathrm{~m}$ in length are normally required to rotate at speeds of less than 3000 RPM to avoid performance degradations owing to sonic airflow conditions at the propeller tips. The CityAirbus (Fig. 6), is powered by eight Siemens SP200Ds which rotate at a relatively slow 1300 RPM. Conversely, the MPS 154120 and the EP 238/50 motor characteristics shown in Fig. 4, indicate motors having high rotational speeds $>4000$ RPM and relatively low torque characteristics. These motors have typical applications on large homebuild UAV drones and powered paragliders respectively and are readily available to purchase as off-the-shelf equipment. Interestingly the UQM Technologies motor uniquely indicates relatively high rotational speed and power characteristics. This motor drive system was adapted from a terrestrial vehicle application for the Rutan Long ESA aircraft in a one-off AEP speed record attempt.

Fig. 7 provides a comparison of the Specific Powers and Efficiencies of the motors listed in Table III.

It shows that the higher output power motors also have higher efficiencies in the range of $93 \%$ to $95 \%$. These motors are exclusively liquid cooled and are synchronous permanent magnet types with slotted distributed windings. The lower efficiency motors have efficiencies in the range of $88 \%$ to $90 \%$ and are air cooled, BLDC permanent magnet types with concentrated windings. Interestingly, a high specific power value does not necessarily indicate good motor efficiency. The air-cooled motors indicating very good specific power values of about $7 \mathrm{~kW} / \mathrm{kg}$.

\section{CONCLUSION}

An overview of the state-of-the-art in motor topologies for AEP has been conducted, and it has been concluded that electrical motors provide an ideal means for achieving aircraft propulsion. Fan and propeller load (torque) characteristics increase gradually with rotor speed which makes them ideal for electrical motor drive applications. The operational ranges of fan and propeller speeds also permit simple, lightweight direct-drive connections to be achieved and with reference to Table III. It can be seen that the specific power values for existing AEP motor technologies range between 4 and $10 \mathrm{~kW} / \mathrm{kg}$ placing them between high-performance piston engine and jet engine technologies when correlated with Table I values. It was further concluded that existing AEP motors rotate at relatively low speed ranges of 1300 to 5000 RPM when compared with civil aircraft turbo-fan engines which typically rotate between 5000 and 7000 RPM. Indicating a limitation in attainable fan efflux velocities and ultimately AEP achievable aircraft speeds. A deduction that is evidenced by the low speed aircraft applications on which current AEP motor technologies are implemented. This also suggests that higher fan and motor speeds are likely to be required for future high speed aircraft designs. To this end, development work is already underway on rim driven fan (RDF) technologies that offer the potential of high efficiency and efflux velocities [27]. The importance of high TRV values (refer to Table II) was also realised when considering the flat disc-like, liquid cooled motor topologies evidenced by the images of the highperformance motors provided in Table III.

\section{REFERENCES}

[1] R.C. Bolam, Y. Vagapov, and A. Anuchin, "Review of electrically powered propulsion for aircraft," in Proc. 53rd Int. Universities Power Engineering Conference (UPEC-2018), Glasgow, UK, 4-7 Sept. 2018, pp. 1-6.

[2] C.A. Luongo, P.J. Masson, T. Nam, D. Mavris, H.D. Kim, G.V Brown, M. Waters, and D. Hall "Next generation more-electric aircraft: A potential application for HTS superconductors," IEEE Trans. on Applied Superconductivity, vol. 19, no. 3, pp. 1055-1068, June 2009.

[3] K. Kovalev, J. Nekrasova, N. Ivanov, and S. Zhurzvlev, "Design of all-superconducting electrical motor for full electric aircraft," in Proc. Int. Conf. on Electrotechnical Complexes and Systems (ICOECS), Ufa, Russia, 21-25 Oct. 2019, pp. 1-5.

[4] M. Rosu, P. Zhou, D. Lin, D. Lonol, M. Popescu, F. Blaabjerg, V. Rallabandi, and D. Staton, Multiphysics Simulation by Design for Electrical Machines, Power Electronics and Drives. Piscataway, NJ: IEEE Press; Hoboken, NJ: Wiley, 2018. 
[5] H.W. Beaty, and J.L Kirtley, Electric Motor Handbook. New York: McGraw-Hill, 1998.

[6] D.G. Dorrell, M. Hsieh, M. Popescu, L. Evans, D.A. Staton, and V. Grout, "A review of the design issues and techniques for radial-flux brushless surface and internal rare-earth permanent-magnet motors," IEEE Trans. on Industrial Electronics, vol. 58, no. 9, pp. 3741-3757, Sept. 2011.

[7] C. Liu, "Emerging electric machines and drives - An overview," IEEE Trans. on Energy Conversion, vol. 33, no. 4, pp. 2270-2280, Dec. 2018.

[8] N. Hashemnia, and B. Asaei, "Comparative study of using different electric motors in the electric vehicles," in Proc. 18th Int. Conf. on Electrical Machines, Vilamoura, Portugal, 6-9 Sept. 2008, pp. 1-5.

[9] W. Cao, B.C. Mecrow, G.J. Atkinson, J.W. Bennett, and D.J. Atkinson, "Overview of electric motor technologies used for more electric aircraft (MEA)," IEEE Trans. on Industrial Electronics, vol. 59, no. 9, pp. 3523-3531, Sept. 2012.

[10] B. Sarlioglu, and C.T. Morris, "More electric aircraft: Review, challenges, and opportunities for commercial transport aircraft," IEEE Trans. on Transportation Electrification, vol. 1, no. 1, pp. 5464, June 2015.

[11] A. Hughes, and B. Drury, Electric Motors and Drives: Fundamentals, Types and Applications, 5th ed. Kidlington: Newnes, 2019.

[12] A. Mujianto, M. Nizam, and Inayati, "Comparation of the slotless brushless DC motor (BLDC) and slotted BLDC using 2D modeling," in Proc. Int. Conf. on Electrical Engineering and Computer Science (ICEECS), Kuta, Indonesia, 24-25 Nov. 2014, pp. 212-214.

[13] J. Seo, J. Kim, I. Jung, and H. Jung, "Design and analysis of slotless brushless DC motor," IEEE Trans. on Industry Applications, vol. 47, no. 2, pp. 730-735, Mar.-Apr. 2011.

[14] M.S. Islam, R. Mikail, and I. Husain, "Slotless lightweight motor for aerial applications," IEEE Trans. on Industry Applications, vol. 55, no. 6, pp. 5789-5799, Nov.-Dec. 2019.

[15] A. Tessarolo, M. Bortolozzi, and C. Bruzzese, "Explicit torque and back EMF expressions for slotless surface permanent magnet machines with different magnetization patterns," IEEE Trans. on Magnetics, vol. 52, no. 8, pp. 1-15, Aug. 2016, Art. no. 8107015.

[16] N. Borchardt, and R. Kasper, "Analytical magnetic circuit design optimization of electrical machines with air gap winding using a Halbach array," in Proc. IEEE Int. Electric Machines and Drives Conference (IEMDC), Miami, FL, USA, 21-24 May 2017, pp. 1-7.

[17] M. Nagrial, J. Rizk, and A. Hellany, "Design and performance of permanent magnet slotless machines," in Proc. 18th Int. Conf. on Electrical Machines, Vilamoura, Portugal, 6-9 Sept. 2008, pp. 1-5.

[18] F. Magagna, and D. Peroni, "New technologies: Aluminium Litz wire," Bagnoli, Italy, De Angeli Prodotti S.r.l., 2017. [Online]. Available: http://www.deangeliprodotti.com/en/system/files/ LITZ_WIRE_aluminium_high_frequencies_2017.pdf

[19] M. Iorgulescu, "Study of single phase induction motor with aluminium versus copper stator winding," in Proc. Int. Conf. on Applied and Theoretical Electricity (ICATE), Craiova, Romania, 6-8 Oct. 2016, pp. 1-5.

[20] S. Ayat, R. Wrobel, J. Baker, and D. Drury, "A comparative study between aluminium and copper windings for a modular-wound IPM electric machine," in Proc. IEEE Int. Electric Machines and Drives Conference (IEMDC), Miami, FL, USA, 21-24 May 2017, pp. 1-8.

[21] F. Giulii Capponi, G. De Donato, and F. Caricchi, "Recent advances in axial-flux permanent-magnet machine technology," IEEE Trans. on Industry Applications, vol. 48, no. 6, pp. 2190-2205, Nov.-Dec. 2012.
[22] S. Huang, J. Luo, F. Leonardi, and T.A. Lipo, “A comparison of power density for axial flux machines based on general purpose sizing equations," IEEE Trans. on Energy Conversion, vol. 14, no. 2, pp. 185-192, June 1999.

[23] N. Balkan Simsir, and H. Bulent Ertan, "A comparison of torque capabilities of axial flux and radial flux type of brushless DC (BLDC) drives for wide speed range applications," in Proc. IEEE Int. Conf. on Power Electronics and Drive Systems, Hong Kong, 2729 July 1999, vol. 2, pp. 719-724.

[24] R. Ghosh, "Performance analysis of a silicon carbide IGBT for SVM PWM induction motor drive applications," in Proc. Devices for Integrated Circuit (DevIC), Kalyani, India, 23-24 March 2017, pp. 522-526.

[25] X. Bian, L. Wang, Y. Liu, Y. Yang, and Z. Guan, "High altitude effect on corona inception voltages of DC power transmission conductors based on the mobile corona cage," IEEE Trans. on Power Delivery, vol. 28, no. 3, pp. 1971-1973, July 2013.

[26] J. Goss, "Performance analysis of electric motor technologies for an electric vehicle powertrain," Wrexham, UK, Motor Design Ltd., White Paper, 2019. [Online]. Available: https://www.motordesign.com/wp-content/uploads/2019/06/Performance-Analysis-ofElectric-Motor-Technologies-for-an-Electric-Vehicle-Powertrain.pdf

[27] R.C. Bolam, and Y.Vagapov, "Implementation of electrical rim driven fan technology to small unmanned aircraft," in Proc. Int. Conf on Internet Technologies and Applications, Wrexham, UK, 12-15 Sept. 2017, pp 35-40.

[28] Safran. (2014). Safran onboard the E-Fan. [Online]. Available: https://www.safran-group.com/media/20140429_safran-onboard-efan

[29] Siemens. (2019). Electric flight. [Online]. Available: https:// press.siemens.com/global/en/feature/electric-flight

[30] YASA, "YASA 750R e-motor," Oxford, UK, YASA Ltd., 2018. [Online]. Available: https:/www.yasa.com/wp-content/ uploads/2018/01/YASA-750-Product-Sheet.pdf

[31] magniX, "Magni 500 specification," Seattle, WA, USA, magniX, 2020. [Online]. Available: https://drive.google.com/file/ d/1jpYiQFfRkH17UKTwgY1OHKZsYmuiJMOX

[32] D. Sigler. (2014). Chip yates' records ratified by FAI. Sustainable Skies. [Online]. Available: http://sustainableskies.org/chip-yatesrecords-ratified-fai/

[33] EMRAX. (2016). EMRAX 348. [Online]. Available: https:// emrax.com/e-motors/emrax-348/\#1482059435797-eb98587f-6c74

[34] Dongguan Freerchobby Co. Ltd. (2017). MP154120 45KW 75Nm Sensored Outrunner Brushless Motor for Electric Car. [Online]. Available: http://www.freerchobby.cc/e productshow/?16-2017MP154120-45KW-75Nm-Sensored-Outrunner-Brushless-Motor-forElectric-Car-16.html

[35] E-Power Hobby. (2017). EP-MAD M40 Electric Paramotor. [Online]. Available: https://epowerhobby.com/product/ep-mad-m40motor/

[36] T. Pallini. (2020). "The world's largest electric plane just took its first flight in the latest milestone for battery-powered passenger flights," Business Insider. [Online]. Available: https:// www.businessinsider.com/magnix-all-electric-cessna-grand-caravantakes-first-flight-2020-6? $\mathrm{r}=\mathrm{US} \& \mathrm{IR}=\mathrm{T}$

[37] B. Garrett-Glaser. (2020). "CityAirbus demonstrator makes first untethered flight," Aviation Today. [Online]. Available: https:// www.aviationtoday.com/2020/01/10/cityairbus-demonstrator-makesfirst-untethered-flight/ 